\title{
Amostragem de acessos introduzidos e melhorados para composição de uma coleção núcleo de milho ${ }^{1}$
}

\author{
Sampling of introduced and improved access to composition of a core collection of \\ corn
}

\author{
Ronaldo Rodrigues Coimbra' ${ }^{2 *}$, Glauco Vieira Miranda ${ }^{3}$, Cosme Damião $\mathrm{Cruz}^{3}$, Derly José Henriques da Silva ${ }^{3}$ e \\ Ramiro Andrade Vilela ${ }^{4}$
}

\begin{abstract}
Resumo - Visando a amostragem de acessos para comporem uma coleção núcleo de milho, foram amostrados acessos introduzidos e melhorados da Coleção Ativa de Germoplasma da Embrapa Milho e Sorgo, localizada em Sete Lagoas, MG. A estratégia de amostragem utilizada foi baseada em análise multivariada, sendo adotada intensidade de amostragem de $20 \%$. A estratificação dos acesos introduzidos foi realizada principalmente de acordo com o país de origem, local de avaliação e tipo de grão. Para os acessos melhorados considerou-se principalmente o tipo de grão e a instituição responsável pela realização do melhoramento do acesso. Verificou-se a necessidade de se realizar a caracterização e avaliação de muitos acessos introduzidos e melhorados. Foi possível observar a existência de variabilidade genética entre os acessos introduzidos e melhorados. As características altura de planta e peso de mil grãos foram as que mais contribuíram para a discriminação dos genótipos. A utilização combinada do método de Tocher tendo como medida de dissimilaridade a distância euclidiana invertida e a análise de dispersão gráfica com base nos três primeiros componentes principais foi eficiente. Foi possível a amostragem de acessos para comporem uma coleção núcleo de milho com base em análise multivariada a partir de dados de caracterização e avaliação.
\end{abstract}

Palavras-chave - Zea mays L. Coleção nuclear. Diversidade. Recursos genéticos.

\begin{abstract}
Aiming at the selection of accessions to compose a core collection of maize, were sampled access introduced and improved of Active Germplasm Bank at Embrapa Milho e Sorgo, located in Sete Lagoas, MG, Brazil. The sampling strategy was based in multivariate analysis, and adopted a sampling rate of $20 \%$ of accesses. Stratification of introduced accessions was in according with the country of origin, place of assessment and type of grain. For improved access was considered mainly the type of grain and the institution responsible for improvement of access. There is a need to perform the characterization and evaluation of many introduced and improved. It was possible to observe the existence of genetic variability among accessions. The plant height and thousand grain weight were the main contributors to the discrimination of genotypes. The combined use of the method of Tocher and as dissimilarity measure the Euclidian distance reversed and graphic dispersion analysis based on the first three principal components was effective. It was possible the selection of accessions to compose a core collection of maize based on multivariate analysis from the characterization and evaluation data.
\end{abstract}

Key words - Zea mays L. Core collection. Diversity. Genetics resources.

\footnotetext{
* Autor para correspondência

${ }^{1}$ Recebido para publicação em 28/07/2010; aprovado em 19/07/2011

Parte da Dissertação de Doutorado do primeiro autor, apresentada ao programa de Pós-Graduação em Genética e Melhoramento da Universidade Federal de Viçosa-UFV

${ }^{2}$ Universidade Federal do Tocantins, Rua 07, Quadra 15, s/n, Jardim dos Ipês, Porto Nacional-TO, Brasil, 77.500-000, ronaldo.rc@uft.edu.br

3Universidade Federal de Viçosa, Viçosa-MG, Brasil,36.570-00, glaucovmiranda@ufv.br, cdcruz@mail.ufv.br, derly@ufv.br

${ }_{4}^{4}$ Pesquisador da Embrapa Milho e Sorgo, Rodovia MG 424, KM 45, Sete Lagoas, MG - BR, 35701-970, ramiro@cnpms.embrapa.br
} 


\section{Introdução}

A partir da metade do século 20, verificou-se aumento no interesse em se conservar recursos genéticos vegetais, o que levou muitos países a adotarem políticas nacionais e internacionais de intercâmbio de germoplasma (GEPTS, 2006). Esse interesse foi devido principalmente à grande perda de recursos genéticos causada pelo mal uso e destruição dos centros de origem e variabilidade genética, pela adoção de cultivares modernos em substituição aos cultivares primitivos e o desenvolvimento de novas práticas e tecnologias agrícolas. Como consequência, temse observado um crescente aumento no número de bancos de germoplasma. Esses bancos encontram-se distribuídos pelos 157 países que compõem a Comissão de Recursos Fitogenéticos da FAO, existindo coleções de várias espécies (VASCONCELOS et al., 2007).

Estima-se que mais de 6,1 milhões de acessos de plantas são conservados em todo o mundo e esses acessos estão dispostos em 1.320 bancos de germoplasma. Em 1998, já existiam no Brasil mais de 200 mil acessos de plantas conservados ex situ, em cerca de 165 bancos de germoplasma implantados em mais de 50 locais (VALOIS, 1998). Esses números mostram o esforço realizado para a conservação de recursos genéticos no Brasil. Entretanto, diante da grande demanda dos fitomelhoristas (ARAUJO; NASS, 2002) não basta apenas conservar, torna-se necessário que essa grande quantidade de informação genética seja disponibilizada.

O grande problema é que na maioria das coleções de germoplasma existe um grande número de acessos armazenados e poucas informações sobre cada acesso (ANDRADE et al., 2002; TEIXEIRA et al., 2002), o que se reveste em desestimulo à utilização dos mesmos. Essa é uma realidade quando se considera várias espécies vegetais, como por exemplo, o milho, pois, de modo geral a quantidade de informações sobre acessos de milho é considerada insuficiente (NETTO et al., 2004).

Uma alternativa para a resolução deste problema é o desenvolvimento de "Coleções Núcleo" (AGRAMA et al., 2009). Segundo Brown e Spillane (1999), uma coleção núcleo é um subconjunto de acessos da coleção de germoplasma, contendo de 10 a $20 \%$ dos genótipos da coleção original, representando de 70 a $80 \%$ da sua diversidade. Neste caso, entende-se por diversidade genética a variação hereditária devido à constituição genética dos indivíduos de uma população, sendo responsável por parte das suas diferenças fenotípicas (FALEIRO, 2007).

No Brasil, existem coleções núcleos de várias espécies, como a Coleção Núcleo de Arroz, formada por 550 acessos (ABADIE et al., 2005) e a de trevo- branco, composta por 75 acessos (BORTOLINE et al., 2006), entre outras.

As coleções núcleo podem ser desenvolvidas utilizando-se várias metodologias, sendo que na maioria das vezes, para se estimar a divergência genética entre acessos são utilizados métodos de análise multivariada, como a análise de componentes principais, variáveis canônicas e métodos aglomerativos. Essas análises são muito utilizadas para determinação da divergência genética em várias espécies (ELIAS, et al., 2007). Um bom exemplo é o trabalho realizado por Bige e Lorenzoni (2007), na Angola, onde os mesmos realizaram a caracterização de 99 acessos amostrados da Coleção Base de Milho, utilizando 36 descritores morfofisiológicos e utilizando metodologias multivariadas, defininindo 11 grupos varietais que servirão como base para o desenvolvimento de uma coleção núcleo de milho.

Diante do exposto, este trabalho teve como objetivo a amostragem de acessos introduzidos e melhorados da Coleção Ativa de Germoplasma da Embrapa Milho e Sorgo para comporem uma coleção núcleo de germoplasma utilizando técnicas de análises multivariadas.

\section{Material e métodos}

No período de julho a outubro de 2001, foram reunidas todas as informações disponíveis sobre os acessos introduzidos e melhorados da Coleção Ativa de Germoplasma da Embrapa Milho e Sorgo, localizada em Sete Lagoas, MG, sendo considerados os dados de passaporte, caracterização e avaliação.

Para a organização do banco de dados, foram realizadas as seguintes etapas:

a. Identificação do tipo de grão dos acessos, sendo considerados apenas acessos contendo grãos do tipo dentado, semi-dentado, duro e semiduro;

b. Estratificação quanto ao tipo de acesso: - Melhorado: Submetido a, pelo menos, um ciclo de seleção; Introduzido: Originário de coleta em outros países;

c. Identificação da instituição responsável pelo desenvolvimento dos acessos melhorados, sendo estes divididos em acessos desenvolvidos pela Embrapa e acessos desenvolvidos por outras instituições;

d. Identificação do país de origem dos acessos introduzidos;

e. Classificação dos acessos quanto à região em que se realizou a avaliação de campo (Sete Lagoas - MG ou Janaúba - MG); 
f. Identificação dos acessos introduzidos originários de regiões de clima temperado e posterior exclusão destes;

g. Verificação da quantidade de sementes disponível de cada acesso. Os acessos com pequena quantidade de sementes e baixa porcentagem de germinação foram desconsiderados;

h. Identificação do número de características disponíveis para cada acesso;

i. Auditoria de dados: descarte de características que apresentaram valores muito discrepantes, pois esses valores geralmente são oriundos de erros de mensuração.

A estratégia de amostragem utilizada foi baseada em análise multivariada, sendo adotada uma intensidade de amostragem de $20 \%$ dos acessos. Os acessos introduzidos foram estratificados quanto à origem geográfica e local de avaliação (Sete Lagoas - MG ou Janaúba - MG). Os acessos melhorados foram estratificados quanto ao local onde se realizou o melhoramento e local de avaliação. $\mathrm{O}$ número de acessos amostrados em cada extrato foi proporcional ao tamanho do extrato. análises:

Em cada extrato, foram realizadas as seguintes

a. Análise de Componentes Principais: O número de variáveis utilizadas variou de acordo com a disponibilidade de informações dentro de cada extrato;

b. Distância Euclidiana "Invertida": Calculou-se a Distância Euclidiana e posteriormente, realizou-se a inversão de valores, ou seja, a maior distância na matriz de dissimilaridade foi subtraída de todas as demais distâncias. Assim, a maior distância passou a ter o menor valor (zero) e conseqüentemente, a menor distância passou a ter o maior valor;

c. Método de Agrupamento de Tocher: Utilizou-se como medida de dissimilaridade a matriz de distâncias Euclidianas "Invertida". Por isso, ao se realizar o agrupamento por essa metodologia, foram agrupados os genótipos mais divergentes, de modo a facilitar a amostragem desses acessos;

d. Análise de Dispersão Gráfica: Foram realizados gráficos a partir dos escores dos primeiros componentes principais. Os acessos mais divergentes de acordo com o método de otimização de Tocher foram identificados nestes gráficos, sendo possível utilizar as duas metodologias de forma combinada. Desta forma, foram amostrados os acessos mais representativos dentro de cada extrato;

e. A importância relativa das características dentro de cada extrato foi determinada pelo método de Singh.

As características previamente avaliadas no banco ativo de germoplasma da Embrapa Milho e Sorgo e consideradas no presente trabalho foram: 1) Tipo de grão (TG): 1 - dentado, 2 - semi-dentado, 3 - duro e 4 - semiduro; 2) Dias para o florescimento masculino (FM, dias): número de dias da emergência das plântulas ao florescimento masculino, contado quando $50 \%$ das plantas da parcela possuíam florescimento masculino; 3) Dias para florescimento feminino (FF, dias): número de dias da emergência das plântulas ao florescimento feminino, contado quando $50 \%$ das plantas na parcela possuíam florescimento feminino; 4) Posição da espiga (POE): posição da espiga em relação ao colmo (1 - ereta, 2 oblíqua e 3 - decumbiente); 5) Número de ramificações do pendão (NRP): número de ramificações primárias na haste principal do pendão; 6) Altura da planta (AP, m): medida em metros após o florescimento masculino, do nível do solo à inserção da folha bandeira; 7) Altura da primeira espiga (AE, m): medida em metros após o florescimento masculino, do nível do solo à inserção da espiga superior no colmo; 8) Porcentagem de plantas quebradas (PPQ): relação entre o número de plantas quebradas na parcela e o estande final, sendo consideradas plantas quebradas aquelas que apresentaram o colmo quebrado abaixo da espiga superior em cada parcela, por ocasião da colheita; 9) Porcentagem de plantas acamadas (PPA): relação entre o número de plantas acamadas na parcela e o estande final, sendo consideradas plantas acamadas, aquelas que apresentaram ângulo de inclinação superior a 45 graus em relação a vertical, na ocasião da colheita; 10) Número de folhas acima da espiga superior (NFE); 11) Número de folhas por planta (NF); 12) Diâmetro do colmo (DC, cm): medido logo acima das raízes adventícias; 13) Número de espigas (NE): número de espigas por parcela; 14) Comprimento da espiga (CE, $\mathrm{mm})$ : comprimento da espiga sem palha; 15) Diâmetro da espiga (DE, mm): medida na parte central da espiga; 16) Número médio de fileiras de grãos (NFG): média do número de fileiras de grãos por parcela; 17) Número médio de grãos por fileira (NGF): média do número de grãos por fileira na parcela; 18) Peso médio de espiga por planta (PEP, mg): média do peso de espigas por planta; 19) Peso de grãos por planta na parcela (PGP, mg); 20) Diâmetro do sabugo (DS, mm): média do diâmetro do sabugo na parcela, medido na parte central do sabugo; e 21) Peso de 1.000 grãos (PMG, mg).

\section{Resultados e discussão}

Ao final de todas as etapas de organização do banco de dados, foram identificados 288 acessos introduzidos de outros países (Introduções) e 222 acessos submetidos a, pelo menos, um ciclo de seleção (Melhorados), correspondendo respectivamente a 12,6 e $9,74 \%$ de toda a coleção ativa de germoplasma, que segundo Andrade etal.(2002), é composta por quase 4.000 acessos e não chega a ser uma das maiores 
coleções de germoplasma quando comparada por exemplo, com a coleção de arroz do USDA-ARS composta por mais de 18.000 acessos (AGRAMA, et al., 2009). Para a maioria dos acessos introduzidos e melhorados, a única informação disponível foram os dados de passaporte. Constatou-se, portanto, a urgente necessidade de se realizar a caracterização e avaliação desses acessos. Consequentemente, dos 510 acessos, 58 Introduzidos (6,32\%) e 54 melhorados (5,88\%) apresentaram informações em quantidade suficiente para serem utilizados no desenvolvimento de uma coleção núcleo baseada em estratificação (TAB. 1; TAB. 2). Posteriormente, à medida que forem geradas informações sobre os demais acessos, poderá se avaliar a possibilidade de inclusão dos mesmos na coleção núcleo.

Tabela 1 - Nome, origem, número do acesso no extrato, local de avaliação e tipo de grão de 58 acessos introduzidos do Bando Ativo de Germoplasma da Embrapa Milho e Sorgo, Sete Lagoas - MG, 2001

\begin{tabular}{|c|c|c|c|c|}
\hline Nome & Origem & $\mathrm{N}^{\mathrm{o}}$. no extrato & Local de Avaliação & Tipo de Grão \\
\hline Guatemala grupo $21-11^{\mathrm{a}}$ & Guatemala & 1 & Janaúba & 2 \\
\hline Guatemala grupo $13-2^{a}$ & Guatemala & 2 & Janaúba & 4 \\
\hline Guatemala grupo $26-1^{\mathrm{a}}$ & Guatemala & 3 & Janaúba & 4 \\
\hline Veracruz grupo 24 & México & 4 & Janaúba & 1 \\
\hline Rep. dominicana grupo 5 & Rep.Dominicana & 5 & Janaúba & 1 \\
\hline Rep. dominicana 275 & Rep.Dominicana & 6 & Janaúba & 1 \\
\hline Rep. dominicana grupo 11 & Rep.Dominicana & 7 & Janaúba & 2 \\
\hline $31106 \mathrm{~g}$ mlws comp & Africa do Sul & 1 & Sete Lagoas & 1 \\
\hline $31126 \mathrm{~g} \mathrm{ph} 4$ & Africa do Sul & 2 & Sete Lagoas & 4 \\
\hline Composto pergam. Araras & Argentina & 3 & Sete Lagoas & 2 \\
\hline Arg v - cateto sulino & Argentina & 4 & Sete Lagoas & 3 \\
\hline Arg vi - canario de 8 & Argentina & 5 & Sete Lagoas & 3 \\
\hline Composto canario de 8 & Argentina & 6 & Sete Lagoas & 3 \\
\hline Colorado pergamino & Argentina & 7 & Sete Lagoas & 3 \\
\hline Compuesto amargo & Argentina & 8 & Sete Lagoas & 4 \\
\hline Teea 64 eeaoc & Argentina & 9 & Sete Lagoas & 4 \\
\hline Tuxpeno caribe & Caribe & 10 & Sete Lagoas & 1 \\
\hline Corn beltxantiguaxR.. Dom. & CIMMYT & 11 & Sete Lagoas & 1 \\
\hline Blanco dentado & CIMMYT & 12 & Sete Lagoas & 1 \\
\hline Chandelle & CIMMYT & 13 & Sete Lagoas & 1 \\
\hline Amarillo del bajio x idones. & CIMMYT & 14 & Sete Lagoas & 2 \\
\hline Amarillo dentado he $\mathrm{o} 2$ & CIMMYT & 15 & Sete Lagoas & 2 \\
\hline Mezcla tropical blanco & CIMMYT & 16 & Sete Lagoas & 2 \\
\hline Cogollero & CIMMYT & 17 & Sete Lagoas & 2 \\
\hline Amarillo cristalino & CIMMYT & 18 & Sete Lagoas & 2 \\
\hline Comiteco & CIMMYT & 19 & Sete Lagoas & 2 \\
\hline Templado amarillo cristal. & CIMMYT & 20 & Sete Lagoas & 3 \\
\hline Templado amarillo qmp & CIMMYT & 21 & Sete Lagoas & 3 \\
\hline Blanco cristalino & CIMMYT & 22 & Sete Lagoas & 3 \\
\hline Eto Colômbia & Colômbia & 23 & Sete Lagoas & 3 \\
\hline Cateto colombia viii & Colômbia & 24 & Sete Lagoas & 3 \\
\hline Guyana 001 & Guiana & 25 & Sete Lagoas & 2 \\
\hline
\end{tabular}


Continuação - Tabela 1

\begin{tabular}{lccll}
\hline Gfr ii - cateto nortista & Guiana Francesa & 26 & Sete Lagoas & 3 \\
Honduras grupo 13 & Honduras & 27 & Sete Lagoas & 2 \\
Kisan & Índia & 28 & Sete Lagoas & 3 \\
Prolifico japonês & Japão & 29 & Sete Lagoas & 2 \\
Olotillo & México & 30 & Sete Lagoas & 1 \\
Zapalote Chico & México & 31 & Sete Lagoas & 1 \\
TUXPENO 1 & México & 32 & Sete Lagoas & 1 \\
VERACRUZ 183 & México & 33 & Sete Lagoas & 2 \\
KALAHARI BLITZ & Namibia & 34 & Sete Lagoas & 1 \\
Paquistão & Paquistão & 35 & Sete Lagoas & 1 \\
PAG I - Semi-dentado Paulista & Paraguai & 36 & Sete Lagoas & 2 \\
COMPOSTO CRUZ CUZCO & Peru & 37 & Sete Lagoas & 2 \\
PUERTO RICO 18 & Porto Rico & 38 & Sete Lagoas & 1 \\
PUERTO RICO GPO 3 & Porto Rico & 39 & Sete Lagoas & 1 \\
SUR I - Cateto Nortista Precoce & Suriname & 40 & Sete Lagoas & 3 \\
SUWAN DMR - Original & Tailândia & 41 & Sete Lagoas & 2 \\
URG VI - Canario de 8 & Uruguai & 42 & Sete Lagoas & 2 \\
URG IV - Cateto Sulino & Uruguai & 43 & Sete Lagoas & 3 \\
URG V-A-Cateto Sulino Escuro & Uruguai & 44 & Sete Lagoas & 3 \\
URG VIII - Cristal Sulino & Uruguai & 45 & Sete Lagoas & 3 \\
STIFF STALCK SYNTETIC & USA & 46 & Sete Lagoas & 1 \\
RALEX ho (M) C16 & USA & 47 & Sete Lagoas & 1 \\
DROUGTH TOLERANT & USA & 48 & Sete Lagoas & 1 \\
HIGH PROTEIN (I.H.P) & USA & 49 & Sete Lagoas & 2 \\
BS 29 & USA & 50 & Sete Lagoas & 2 \\
YELLOW FLINT HE O2 & USA & 51 & Sete Lagoas & 3 \\
\hline
\end{tabular}

Tabela 2 - Nome, número do acesso no extrato, local de melhoramento e tipo de grão de 54 acessos melhorados do Bando Ativo de Germoplasma da Embrapa Milho e Sorgo, Sete Lagoas - MG, 2001

\begin{tabular}{lccc}
\hline \multicolumn{1}{c}{ Nome } & $\mathrm{N}^{\circ}$ no extrato & Local de Melhoramento & Tipo de grão \\
\hline BR 105 - Suwan DMR & 1 & CNPMS & 2 \\
Restrito 66 & 2 & CNPMS & 1 \\
BR 125 - Cateto Colombia & 3 & CNPMS & 3 \\
BR 126 - Dentado COMP. & 4 & CNPMS & 1 \\
BR 126 XIII & 5 & CNPMS & 2 \\
BR 5101 & 6 & CNPMS & 1 \\
BR 5102 & 7 & CNPMS & 2 \\
CATETO SETE LAGOAS & 8 & CNPMS & 3 \\
Restrito 21 & 9 & Outras & 2 \\
AMARELO DE PE A2 & 10 & Outras & 2 \\
AMARELO SERTAO & 11 & Outras & 2 \\
BAIER & 12 & Outras & 2 \\
\hline
\end{tabular}


Continuação - Tabela 2

\begin{tabular}{|c|c|c|c|}
\hline CATETO PROLIFICO IX & 13 & Outras & 3 \\
\hline CENTRALMEX & 14 & Outras & 1 \\
\hline COMP. AMPLO & 15 & Outras & 2 \\
\hline ESALQ PB 1 & 16 & Outras & 2 \\
\hline ESALQ VD-2 & 17 & Outras & 1 \\
\hline FLINT COMP. CMI HSI & 18 & Outras & 3 \\
\hline Restrito 26 & 19 & Outras & 1 \\
\hline JATINA C3 ANAO & 20 & Outras & 1 \\
\hline Restrito 27 & 21 & Outras & 1 \\
\hline PIRAMEX RIO PRETO & 22 & Outras & 2 \\
\hline PIRANAO & 23 & Outras & 1 \\
\hline RELIANCE B & 24 & Outras & 1 \\
\hline SC I - Dente Riograndense Liso & 25 & Outras & 1 \\
\hline SC II - Dente Branco Riograndense & 26 & Outras & 1 \\
\hline Restrito 64 & 27 & Outras & 3 \\
\hline WP 1 - Flint COMP. & 28 & Outras & 2 \\
\hline WP 10 - Hawai SLP & 29 & Outras & 1 \\
\hline WP 11 - Flint Dent. & 30 & Outras & 2 \\
\hline WP 12 - Tuxp - Flint & 31 & Outras & 1 \\
\hline WP 13 - Comp. Caribe & 32 & Outras & 2 \\
\hline WP 14 - Cristalinos & 33 & Outras & 2 \\
\hline WP 15 - Sint. Amar. Cr. & 34 & Outras & 1 \\
\hline WP 17 - Antigua GP2 & 35 & Outras & 2 \\
\hline WP 18 - Tuxp. Amar. Cr. & 36 & Outras & 1 \\
\hline WP 19 - Tuxp. Cuba & 37 & Outras & 1 \\
\hline WP 2 - Amarelo Dent. & 38 & Outras & 1 \\
\hline WP 20 - Tuxpantigua & 39 & Outras & 1 \\
\hline WP 21 - COMP. Cuba & 40 & Outras & 2 \\
\hline WP 23 - Azteca Antigua & 41 & Outras & 2 \\
\hline WP 25 - La Posta & 42 & Outras & 1 \\
\hline WP 26 - Capitein & 43 & Outras & 1 \\
\hline WP 27 - Cuba 28 & 44 & Outras & 1 \\
\hline WP 28 - Diacol V 101 & 45 & Outras & 1 \\
\hline WP 29 - Carmen & 46 & Outras & 1 \\
\hline WP 3 - Cuprico & 47 & Outras & 2 \\
\hline WP 30 - Narino 330 & 48 & Outras & 1 \\
\hline WP 31 - Peru 330 x Narino 330 & 49 & Outras & 2 \\
\hline WP 37 - Venezuela 3 & 50 & Outras & 1 \\
\hline WP 6 - Tuxpeno x Eto & 51 & Outras & 1 \\
\hline WP 7 - Eto Branco & 52 & Outras & 2 \\
\hline WP 8 - Cuba GPO 1 & 53 & Outras & 3 \\
\hline WP 9 - Mix 1 GPO1 x EB & 54 & Outras & 1 \\
\hline
\end{tabular}


O fato de que para muitos acessos não existirem dados de caracterização e avaliação é um problema muito comum em muitas coleções de germoplasma, o que limita a utilização destes para o desenvolvimento de coleções núcleo e conseqüentemente em programas de melhoramento genético. Segundo Li et al. (1998), os fatores que dificultam a utilização de germoplasma são a não disponibilidade dos acessos aos melhoristas, a falta de conhecimentos sobre os acessos conservados e o não conhecimento dos curadores sobre os programas de melhoramento desenvolvidos pelos melhoristas.

Em toda a coleção ativa foram identificados acessos provenientes de 39 países (África do Sul, Guiana Francesa, Paquistão, Argentina, França, Paraguai, Bolívia, Haiti, Peru, Bulgária, Honduras, Porto Rico, Caribe, Hungria, Portugal, Chile, Índia, República Dominicana, Cuba, Itália, Romênia, Jamaica, Suriname, Colômbia, Japão, Tailândia, El Salvador, México, Checoslováquia, Espanha, Namíbia, Uruguai, Guatemala, Nicarágua, Estados Unidos, Guiana, Panamá e Venezuela), além de acessos oriundos do CIMMYT, para os quais não se dispõe de dados referentes à origem geográfica.

Os 58 acessos introduzidos considerados são originários de 21 países e alguns oriundos do CIMMYT (TAB. 1). Acessos introduzidos originários de regiões de clima temperado não foram considerados por apresentarem pequena quantidade de sementes e dificuldade de multiplicação devido a fatores climáticos, além de não serem o germoplasma alvo para o desenvolvimento da coleção núcleo, uma vez que se busca que a coleção núcleo posteriormente sirva de base para o melhoramento genético de milho para condições de clima tropical.

Segundo Brown e Spillane (1999) coleções núcleo são criadas para representar toda a variabilidade genética existente em uma coleção de germoplasma, entretanto, pode-se também desenvolvê-las com o intuito de representar apenas parte desta coleção, visando assim, atender a objetivos específicos. Por isso, nesse trabalho foram considerados apenas acessos com grãos do tipo dentado, semi-dentado, duro e semiduro, não sendo considerados, por exemplo, acessos com grãos do tipo pipoca e farináceo.

A estratificação quanto ao país de origem dos acessos introduzidos baseia-se no trabalho de Hodgkin (1995), que afirma que análises climáticas, ecológicas e informações geográficas sobre as espécies podem ser utilizadas para identificar diferentes ambientes, além de identificar onde foram realizadas coletas excessivas e locais onde devem ser realizadas as futuras coletas. Além dele, Abadie et al. (1997) observaram que a origem ecogeográfica e o tipo de grão foram eficazes para discriminar os acessos landraces de milho brasileiros. Bige e Lorenzoni (2007) também consideraram o local de origem dos acessos como um dos principais critérios para a caracterização de germoplasma de milho na Angola, assim como Yao et al. (2008) para desenvolverem uma coleção núcleo de milho na China, utilizando acessos landraces.

Quando se trabalha com recursos genéticos, entende-sepor “avaliação", a mensuraçãodecaracterísticas quantitativas de acessos de uma determinada espécie em um determinado ambiente. Essas características sofrem fortes influências ambientais, são governadas por poucos ou muitos genes e não são facilmente manipuladas, porém, são úteis no processo de melhoramento genético (RAMOS et al., 2007). Por isso, a estratificação quanto ao local de avaliação justifica-se pela existência da interação genótipo x ambiente. Consequentemente, para minimizar o efeito dessa interação os acessos avaliados em locais diferentes foram alocados em extratos distintos. Ou seja, dos 58 acessos introduzidos, 7 foram avaliados em Janaúba e 51 em Sete Lagoas.

Em relação ao tipo de grão, 18 acessos apresentam endosperma dentado, 19 semi-dentado, 16 duro e 5 semiduro (TAB. 1). Segundo Brieger (1958), acessos de milho com tipo de grãos diferentes possuem origem evolucionária diferente. Por isso, o tipo de grãos também foi utilizado como critério de amostragem dos acessos.

O agrupamento dos acessos avaliados em Janaúba utilizando-se o método de otimização de Tocher, tendo como medida de dissimilaridade a distância Euclidiana "Invertida" foi realizado utilizando-se características comuns a todos os acessos do referido extrato, sendo elas: FM, FF, NRP, AP, NFE, NF, DC, DE, NFG, NGF, PEP, PGP, DS e PMG. Optou-se por visualizar a dispersão gráfica dos acessos com base nos três primeiros componentes principais, de modo a se utilizar o máximo possível da variação dos dados, sendo explicada $81,69 \%$ da variação total (FIG. 1).

Embora os acessos 4 (Veracruz grupo 24) e 6 (Rep. Dominicana 275) apresentem o mesmo tipo de grão (Dentado), foram os mais divergentes nesse extrato (FIG. 1), sendo portanto amostrados. Podese observar ainda a formação de um subgrupo com os acessos 1 (Guatemala grupo 21-11 $1^{\mathrm{a}}$ ), 2 (Guatemala grupo 13-2 $2^{\mathrm{a}}$ ), 3 (Guatemala grupo 26-1 ${ }^{\mathrm{a}}$ ), 5 (Rep. Dominicana grupo 5) e 7 (Rep. Dominicana grupo 11). Portanto, visando a representação da informação genética desse subgrupo o acesso 1, que foi o mais divergente em relação aos acessos 6 e 4, e que possui grão do tipo semi-dentado, também foi amostrado. Observa-se que os acessos que melhor representam a variabilidade genética do extrato são oriundos do México, República Dominicana e Guatemala.

De acordo com o método de Singh, as características que mais contribuíram para a discriminação dos acessos 
avaliados em Janaúba foram a AP, PEP, PGP e PMG. Em trabalho realizado por Netto et al. (2004) ao fazerem a caracterização agronômica de acessos de milho verificaram que as características peso de mil grãos e peso de espigas também estavam entre as que mais contribuíram para a discriminação genotípica, além da altura da espiga.

O agrupamento dos acessos avaliados em Sete Lagoas, de acordo com o método de Tocher tendo como medida de dissimilaridade a distância Euclidiana e a análise de componentes principais, foi realizada considerando-se as características FM, FF, RNP, AP, NFE, NF, DC, DE, NFG, NGF, DS e PMG. Nesta análise verificou-se que, os três primeiros componentes principais explicaram $60,68 \%$ (FIG. 2).

De acordo com o método de Tocher, os acessos mais divergentes foram o: 31 (Zapalote Chico), dentado; 40 (SUR I - Cateto Nortista Precoce), duro; 25 (Guyana 001), semi-dentado, 30 (Olotillo), dentado, 6 (Rep. dominicana 275), dentado; 19 (Comiteco), semi-dentado, 50 (BS 29), semi-dentado, 13 (Chandelle), dentado; 33 (Veracruz 183), semi-dentado e 49 (High Protein (I.H.P)), semi-dentado. Entretanto, pode-se observar no gráfico de dispersão que os acessos 06, 13 e 49 apresentam alta similaridade genética. O mesmo ocorreu entre os acessos 25 e 33. Observa-se também a formação de um subgrupo na região central do gráfico contendo grande parte dos

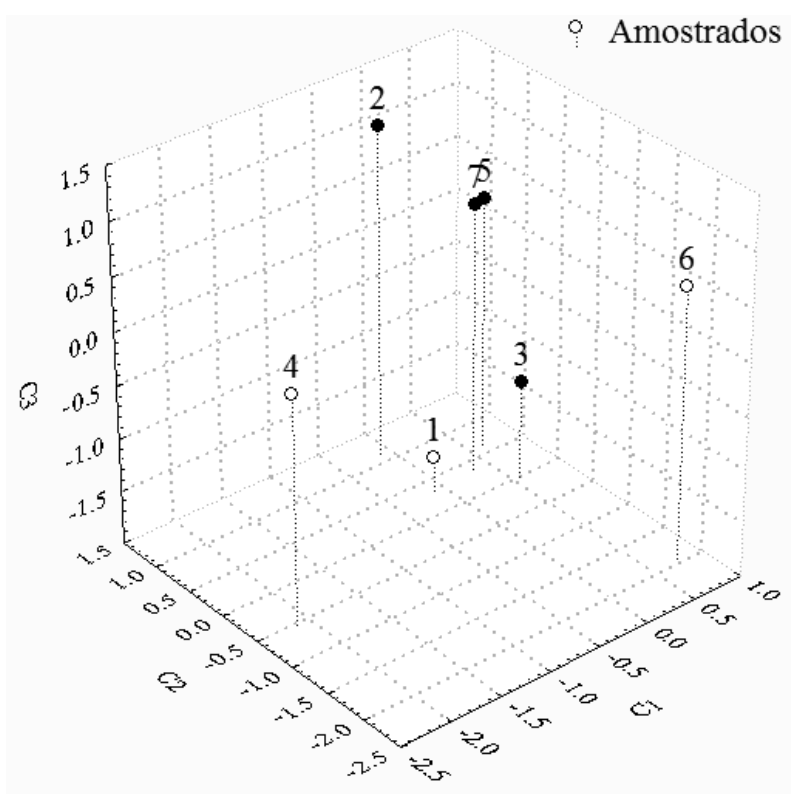

Figura 1 - Gráfico de dispersão de sete acessos introduzidos considerando-se os três primeiros componentes principais e identificação dos acessos amostrados de acordo como o método de otimização de Tocher, tendo como medida de dissimilaridade a distância Euclidiana "Invertida" acessos e que também deve ser amostrado, de forma a melhor representar a variabilidade do extrato.

Um dos fatores que pode ser considerado no momento de amostragem dos acessos para a formação de uma coleção núcleo é o conhecimento prévio do curador ou melhorista em relação à coleção de germoplasma. Por isso, optou-se por manter a amostragem do acesso 6, por ele ser o mais divergente e o 49 por ser reconhecidamente fonte de genes para o melhoramento visando alto teor de proteínas no grãos. Consequentemente, em lugar do acesso 13, foi amostrado o 28 (Kisan), que possui endosperma duro. Em relação aos acessos 25 e 33, foi amostrado apenas o 25, e em lugar do 33, amostrou-se o acesso 7 (Colorado pergamino), dentado.

Os resultados mostram a compatibilidade entre resultado do agrupamento realizado de acordo como o método de Tocher, tendo como medida de dissimilaridade a distância euclidiana invertida e o gráfico de dispersão genotípica elaborado com base nos escores dos três primeiros componentes principais.

As características AP e PMG foram as que mais contribuíram para a discriminação dos acessos nesse extrato, diferentemente do que aconteceu no extrato de Janaúba onde a características PEP, PGP, também foram importantes na discriminação genotípica.

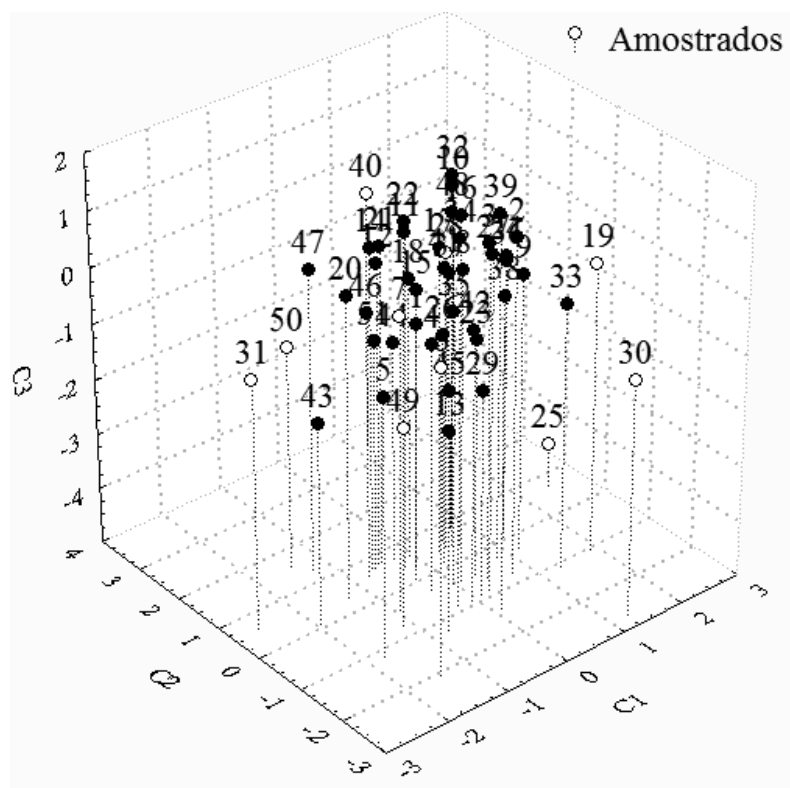

Figura 2 - Gráfico de dispersão de 51 acessos introduzidos de milho considerando-se os três primeiros componentes principais e identificação dos acessos amostrados de acordo como o método de otimização de Tocher, tendo como medida de dissimilaridade a distância Euclidiana "Invertida" 
Observa-se que os acessos que melhor representam a variabilidade genética do extrato são oriundos do México, Suriname, Guiana, República Dominicana, CIMMYT, USA e Índia, perfazendo um total de 12 acessos introduzidos amostrados.

Os acessos melhorados formaram um único extrato em relação ao local de avaliação, uma vez que, todos os acessos foram avaliados em Sete Lagoas. Na estratificação quanto a instituição responsável pelo desenvolvimento dos acessos melhorados, foram observados dois grupos, um contendo 8 acessos desenvolvidos pela Embrapa Milho e Sorgo e outro contendo 46 acessos desenvolvidos por outras instituições.

De acordo com Abadie et al. (2000), acessos desenvolvidos na Embrapa Milho e Sorgo e os oriundos de outros programas de melhoramento, foram agrupados em grupos distintos quando se realizou análise de componentes principais utilizandose dados de caracterização e avaliação. Os acessos melhorados na Embrapa Milho e Sorgo foram obtidos após 1976, ano de criação da Embrapa. Sobre estes acessos, o germoplasma elite do CIMMYT teve grande influência. Os acessos oriundos de outros programas de melhoramento são relativamente mais antigos, e sobre eles o germoplasma do CIMMYT teve menor influência.

No intuito de verificar se para os acessos em questão, os acessos melhorados pela Embrapa e desenvolvidos por outras instituições formavam grupos distintos, realizou-se o agrupamento pelo método de Tocher utilizando-se a distância euclidiana como medida de dissimilaridade e análise de componentes principais, utilizando-se as características FM, FF, NRP, AP, NFE, DC, DE, NFG, NGF, DS e PMG. No gráfico realizado a partir dos escores dos três primeiros componentes principais, considerando $54,84 \%$ da variação total, podese observar que não foram obtidos dois grupos distintos, ou seja, um grupo somente com acessos melhorados na Embrapa e outro com acessos melhorados em outras instituições. Além disso, pelo fato de todos os acessos melhorados terem sido avaliados em Sete Lagoas não se considerou estratificação, sendo os acessos melhorados amostrados como um único extrato.

Quanto ao tipo de grãos dos acessos melhorados, 27 acessos possuem endosperma dentado, 21 semidentado, 6 duro e nenhum semi-duro. Portanto, a grande maioria dos acessos melhorados possuem endosperma dentado e semi-dentado.

Ao se realizar o agrupamento de acordo com o método de Tocher, verificou-se que os acessos 35 (WP 17 - Antigua GP2), semi-dentado; 6 (BR 5101), dentado; 46 (WP 29 - Carmen), dentado; 5 (BR 126 XIII), semi-

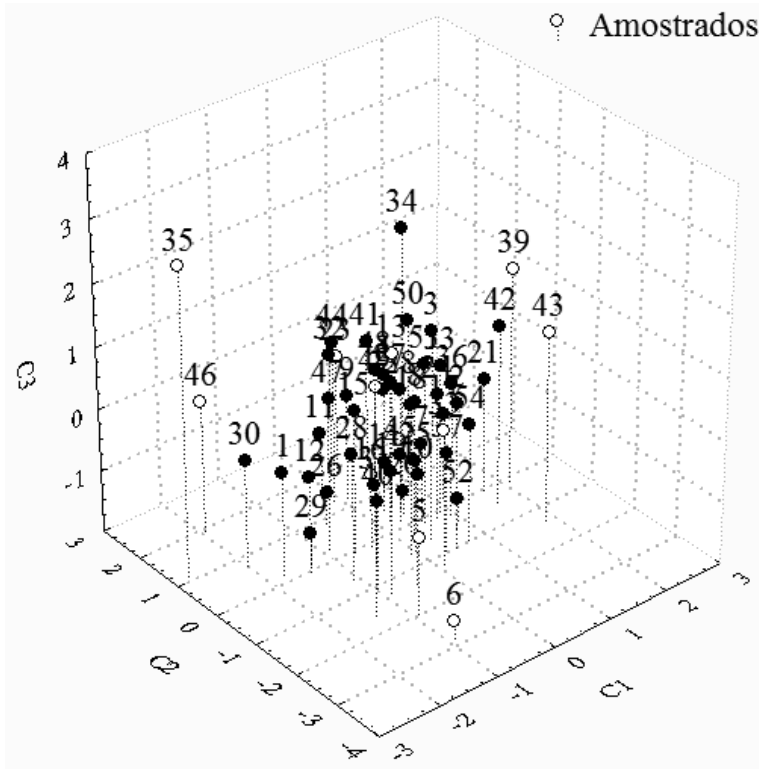

Figura 3 - Gráfico de dispersão de 54 acessos melhorados considerando-se os três primeiros componentes principais e identificação dos acessos amostrados de acordo como o método de otimização de Tocher, tendo como medida de dissimilaridade a distância Euclidiana "Invertida"

dentado; 49 (WP 31 - Peru 330 x Narino 330), semidentado; 39 (WP 20 - Tuxpantigua), dentado; 43 (WP 26 - Capitein), dentado; 14 (CENTRALMEX), dentado; 13 (CATETO PROLIFICO IX), duro e 20 (JATINA C3 ANAO), dentado, e 33 (WP 14 - Cristalinos), semi-dentado, foram os mais divergentes. Entretanto, embora divergentes em relação à maioria dos acessos do extrato, os acessos 20 e 14 apresentam relativa similaridade em relação aos acessos 39 e 43, e o mesmo ocorre entre os acessos 13 e 49. Consequentemente, visando uma melhor representatividade do extrato, em lugar dos acessos 20, 14, foram amostrados os acessos 16 (ESALQ PB 1), semi-dentado; 23 (PIRANAO), respectivamente. Optou-se por manter a amostragem do acesso 13 devido este ser o único entre os mais divergentes com grãos do tipo duro.

De acordo com a metodologia de Singh, as características AP e PMG foram as que apresentaram maior importância relativa para a discriminação dos acessos. Observa-se portanto que tanto para acessos introduzidos e melhorados as características AP e PMG estão entre as que mais contribuem para se mensurar a divergência genética entre os acessos.

Ao se utilizar uma intensidade de amostragem de $20 \%$ dos acessos, foram amostrados 11 acessos melhorados. Entre os acessos amostrados, encontram-se 
2 acessos desenvolvidos pela Embrapa Milho e Sorgo e 9 desenvolvidos por outras instituições. Observa-se que a intensidade de amostragem utilizada em trabalhos que visam o desenvolvimento de coleções núcleo variam entre 5 e 30\% dos acessos da coleção total. Por exemplo, Li et al. (2004), considerando dados de passaporte e de caracterização, desenvolveram na China uma coleção núcleo à partir da Coleção Base de Milho que é composta por 13.521 acessos landraces e de 3.258 linhagens. A coleção desenvolvida foi composta por 951 acessos landraces e 242 linhagens, o que equivale a uma intensidade de amostragem de 7,1\%.

\section{Conclusões}

1. Há a necessidade de se realizar a caracterização e avaliação de muitos acessos introduzidos e melhorados da coleção de germoplasma da Embrapa Milho e Sorgo. Existe variabilidade genética entre os acessos introduzidos e melhorados da coleção ativa de germoplasma de Embrapa Milho e Sorgo. As características altura de planta e peso de mil grãos foram as que mais contribuíram para a discriminação dos genótipos;

2. A utilização combinada do método de Tocher tendo como medida de dissimilaridade a distância euclidiana invertida e a análise de dispersão gráfica com base nos três primeiros componentes principais foi eficiente;

3. Foi possível a amostragem de acessos para compore uma coleção núcleo de milho com base em análise multivariada à partir de dados de caracterização e avaliação.

\section{Referências}

ABADIE, T. et al. A coleção núcleo de germoplasma de milho para o Brasil. Brasília, Embrapa, 2000. 37 p (Boletim de Pesquisa, n. 08).

ABADIE, T. et al. Construção de uma coleção nuclear de arroz para o Brasil. Pesquisa Agropecuária Brasileira, v. 40, n. 02, p. 129-136, 2005.

ABADIE, T. et al. Obtenção e tratamento analítico de dados para organizar coleção núcleo de milho. Brasília: EmbrapaCENARGEN, 1997. 18 p. (Comunicado Técnico, n. 20)

AGRAMA, H. A. et al. Genetic assessment of a mini-core subset developed from the USDA Rice Genebank. Crop Science, v. 49, n. 06 , p. 1336-1346, 2009.

ANDRADE, R. V. et al. Avaliação de acessos de milho crioulo coletados na região central do Brasil. Revista Brasileiro de Milho e sorgo, v. 01, n. 02, p. 67-74, 2002.
ARAUJO, P. M.; NASS, L. L. Caracterização e avaliação de populações de milho crioulo. Scientia Agricola, v. 59, n. 03, p. 589-593, 2002.

BIGE, T.; LORENZONI, C. Characterization of maize (Zea mays L.) germplasm of Angola. Maydica, v. 52, p. 135-144, 2007.

BORTOLINE, F. B. et al. Caracterizações morfológica e agronômica e divergência genética em germoplasma de trevo-branco. Revista Brasileira de Zootecnia, v. 35, n. 02, p.1601-1610, 2006.

BRIEGER, A. H. D. et al. Races of maize in Brazil and other Eastern South American countries. National Academy of Sciences-National Research Council Publication, n. 593, 1958.

BROWN, A. H. D.; SPILLANE, C. Implementing core collections: principles, procedures, progress, problems and promise. In: JOHNSON, R. C.; HODGKIN, T. (Ed.) Core collections for today and tomorrow. Rome: International Plant Genetic Resources Institute, 1999. p. 1-9.

ELIAS, H. T. et al. Variabilidade genética em germoplasma tradicional de feijão-preto em Santa Catarina. Pesquisa Agropecuária Brasileira, v. 42, n. 10, p. 1443-1449, 2007.

FALEIRO, F. G. Marcadores genético-moleculares aplicados a programas de conservação e uso de recursos genéticos. Planaltina: EMBRAPA Cerrados, 2007. 102 p.

GEPTS, P. Plant genetic resources conservation and utilization: the accomplishments and future of a societal insurance policy. Crop Science, v. 46, n. 05, p. 2278-2292, 2006.

HODGKIN, T. et al. (Ed.). Core collections of plant genetic resources. New York: John Wiley, 1995. p. 155-167.

LI, Y. et al. Establishment of a core collection for maize germplasm preserved in Chinese National Genebank using geographic distribution and characterization data. Genetic Resources and Crop Evolution, v. 51, n. 08, p. 845-852, 2004.

LI, Y. et al. The use of genetic resources in crop improvement: Lessons from China. Genetic Resources and Crop Evolution, v. 45, n. 02, p. 181-186, 1998.

NETTO, D. A. M. et al. Avaliação agronômica e molecular de acessos da coleção Núcleo de milho, subgrupo endosperma duro. Revista Brasileira de Milho e Sorgo, v. 03, n. 01, p. 92-107, 2004.

RAMOS, S. R. R.; QUEIROZ, M. A.; PEREIRA, T. N. S. Recursos genéticos vegetais: manejo e uso. Magistra, v. 19, n. 04, p. 265-273, 2007.

TEIXEIRA, F. F. et al. Diversidade no germoplasma de milho coletado na região Nordeste do Brasil. Revista Brasileira de Milho e Sorgo, v. 01, n. 03, p. 59-67, 2002.

VALOIS, A. C. C. Biodiversidade, biotecnologia e propriedade intelectual. Caderno de Ciência \& Tecnologia, v. 15, p. 21-31, 1998. Número especial. 
VASCONCELOS, E. S. et al. Estratégias de amostragem e estabelecimento de coleções nucleares. Pesquisa Agropecuária Brasileira, v. 42, n. 04, p. 507-514, 2007.
YAO, Q.; FAN, P.; ZOU, S. Constructing a core collection for Maize (Zea mays L.) landrace from Wuling Mountain Region in China. Agricultural Sciences in China, v. 07, n. 12, p. 1423-1432, 2008. 